\title{
Analisis Tingkat Kerawanan Longsor Dengan Integrasi Analytical Hierarchy Process dan Pemodelan Spasial Sistem Informasi Geografis di Kabupaten Aceh Tenggara
}

\author{
Juni Muchlis Mustafa ${ }^{1, *}$, Sirojuzilam ${ }^{2}$ Nurdin Sulistiyono $^{3}$ \\ 1,2Program Studi Perencanaan Wilayah Pedesaan Sekolah PascaSarjana, Universitas Sumatera Utara \\ ${ }^{3}$ Fakultas Kehutanan, Universitas Sumatera Utara \\ *Koresponden email: jondaleh@gmail.com
}

Diterima: 25 Maret 2019

Disetujui: 29 Maret 2019

\begin{abstract}
Southeast Aceh District in Aceh Province is a district that often experiences landslides. High rainfall (> 1600 $\mathrm{mm} /$ year) and hilly areas with slope levels above $40 \%$ are also indicators of landslide vulnerability. The study aims to determine the criteria for the biggest contributors to landslide vulnerability using the Analytical Hierarchy Process (AHP) method and find out the distribution of landslide vulnerability in Southeast Aceh District by using spatial modeling using Geographic Information Systems (GIS). Spatial data as a parameter in making landslide models includes 4 (four) parameters, they are land cover, rainfall, slope and soil movement. These parameters have sub-parameters such as land cover parameters that have sub-parameters, i.e empty land, shrubs, rice fields, fields/moor, gardens, settlements, rivers, secondary forests and primary forests. The slope parameters have sub-parameters i.e slope $0-8 \%$, slope of $8-15 \%$, slope of $15-25 \%$, slope of $25-45 \%$, slope $>45 \%$. Rainfall parameters have sub-parameters which are 2,500-2,700 mm/yr, 2,700-2,900 mm/yr, 2,900-3,400 mm/ $\mathrm{yr}, 3,400-3,600 \mathrm{~mm} / \mathrm{yr}$ and 3,600-3800 mm/yr. The parameters of soil motion have sub-parameters, i.e middle and middle high movements. These parameters and sub-parameters become questionnaires by Expert Choice 11 as Analytical Hierarchy Process (AHP) software. This questionnaire then becomes an interview material for expert experts to determine the weight values (parameters) and scores (sub-parameters). The weight values and scores obtained from the Expert Choice 11 application are used by the ArcGIS 10.6 to create a spatial model of the distribution of landslide vulnerabilities. Research has produced spatial distribution of landslide vulnerability with a low level of vulnerability distribution of 209,523.56 ha (49\%), moderate vulnerability of $158,170.14$ ha (37\%) and high vulnerability of 56,640.76 (13\%).
\end{abstract}

Keywords: spatial analysis, Analytical Hierarchy Process (AHP), landslide vulnerability, Geographic Information System (GIS), Aceh Tenggara

\begin{abstract}
Abstrak
Kabupaten Aceh Tenggara di Provinsi Aceh adalah kabupaten yang sering mengalami bencana tanah longsor. Curah hujan yang tinggi ( $>1600 \mathrm{~mm} /$ tahun) dan kawasan berbukit dengan tingkat kemiringan lereng diatas $40 \%$ juga menjadi indikator kerawanan tanah longsor. Penelitian bertujuan mengetahui kriteria penyumbang kerawanan longsor terbesar dengan menggunakan metode Analytical Hierarchy Process (AHP) dan mengetahui sebaran kerawanan longsor di Kabupaten Aceh Tenggara dengan pemodelan spasial menggunakan Sistem Informasi Geografis (SIG). Data spasial sebagai parameter dalam pembuatan model longsor meliputi 4 (empat) parameter yaitu parameter tutupan lahan, curah hujan, kemiringan lereng dan pergerakan tanah. Parameterparameter ini mempunyai sub-parameter seperti parameter tutupan lahan mempunyai sub-parameter yaitu tanah kosong, semak belukar, sawah, ladang/tegalan, kebun, permukiman, sungai, hutan sekunder dan hutan primer. Parameter kemiringan lereng mempunyai sub-parameter yaitu kemiringan 0-8 \%, kemiringan 8-15\%, kemiringan $15-25 \%$, kemiringan $25-45 \%$, kemiringan $>45 \%$. Parameter curah hujan mempunyai sub-parameter yaitu $2.500-2.700 \mathrm{~mm} / \mathrm{thn}, 2.700-2.900 \mathrm{~mm} / \mathrm{thn}, 2.900-3.400 \mathrm{~mm} / \mathrm{thn}, 3.400-3.600 \mathrm{~mm} / \mathrm{thn}$ dan 3.600-3800 $\mathrm{mm} / \mathrm{thn}$. Parameter gerakan tanah mempunyai sub-parameter yaitu gerakan menengah dan menengah-tinggi. Parameter dan sub-parameter ini menjadi kuisioner oleh aplikasi Expert Choice 11 sebagai perangkat lunak Analytical Hierarchy Process (AHP). Kuisioner ini kemudian menjadi bahan wawancara kepada narasumber ahli (expert) untuk menentukan nilai bobot (parameter) dan skor (sub-parameter). Nilai bobot dan skor yang diperoleh dari aplikasi Expert Choice 11 digunakan oleh aplikasi ArcGIS 10.6 untuk membuat model spasial
\end{abstract}


sebaran kerawanan longsor. Penelitian telah menghasilkan sebaran spasial kerawanan longsor dengan sebaran tingkat kerentanan rendah 209.523,56 Ha (49\%), kerentanan sedang 158.170,14 Ha (37\%) dan kerentanan tinggi 56.640,76 (13\%).

Kata kunci: analisis spasial, Analytical Hierarchy Process (AHP), kerawanan longsor, Sistem Informasi Geografis (SIG), Aceh Tenggara

\section{Pendahuluan}

Longsor adalah gerakan tanah yang dipengaruhi gaya tarik bumi (gravitasi) dan juga disebabkan rayapan tanah serta longsoran tanah pada daerah-daerah dengan gerakan tanah tinggi. Pada lereng-lereng pegunungan sering terjadi gerak yang lambat menuju ke arah lembah dimana gerak ini terjadi jika musim penghujan. Kabupaten Aceh Tenggara di Provinsi Aceh telah mengalami sedikitnya 27 kali bencana tanah longsor selama kurun waktu 20122017 (BPBD, 2012, 2017). Curah hujan yang tinggi (>1600 mm/tahun) dan kawasan yang berbukit juga menjadi indikator kerawanan tanah longsor di Kabupaten ini. Tujuan dari penelitian ini adalah: (a). mengetahui kriteria/faktor penyumbang kerawanan longsor terbesar dengan menggunakan metode Analytical Hierarchy Process (AHP) (b). mengetahui sebaran kerawanan longsor di Kabupaten Aceh Tenggara dengan pemodelan spasial menggunakan Sistem Informasi Geografis (SIG).

\section{Tinjauan Pustaka}

\subsection{Analytical Hierarchy Process (AHP)}

Metode AHP diperkenalkan oleh Saaty (1980) dan telah digunakan untuk menganalisis keputusan tentang berbagai isu di bidang teknologi, ekonomi, dan sosiopolitik (Hummel et al. 1998). AHP adalah teknik pengambilan keputusan multi-kriteria yang cocok untuk mendapatkan penilaian kolektif dalam penelitian yang kompleks. Responden dalam AHP adalah orangorang yang dianggap ahli atau sangat familiar dengan kondisi longsor yang terjadi disekitarnya. Nilai bobot dan skor pada AHP harus memiliki nilai inkonsistensi jawaban yaitu $<0.1$, jika tidak terpenuhi maka analisis harus diulang sampai memenuhi nilai inkonsistensi.

\subsection{Sistem Informasi Geografis (SIG)}

Sistem Informasi Geografis (SIG) merupakan suatu sistem (berbasiskan komputer) yang digunakan untuk menyimpan dan memanipulasi informasi-informasi geografis. SIG dirancang untuk mengumpulkan, menyimpan dan menganalisis obyek-obyek dan fenomena dimana lokasi geografis merupakan karakteristik yang memiliki empat kemampuan berikut dalam menangani data yang bersifat rutgeografi: (a) masukan, (b) manajemen data (penyimpanan dan pengambilan data), (c) analisis dan manipulasi data, (d) keluaran (Aronoff, 1989).

\subsection{Model Analisis Tingkat Kerawanan Longsor}

Nilai bobot dan skor dari penilaian AHP diperingkatkan dari yang paling tinggi sampai yang paling rendah sebanding dengan tingkat bahaya yang tanah longsor. Semakin tinggi bobot dan skor, maka semakin tinggi pula potensi tanah longsor yang akan terjadi. Model yang digunakan untuk menganalisis kerawanan longsor adalah model pendugaan yang mengacu pada penelitian BBSDLP (2009) dengan formula dalam persamaan (1) sebagai berikut:

Skor total $=0,2 \mathrm{FCH}+0,25 \mathrm{HJB}-0,2 \mathrm{FKL}+0,1 \mathrm{FPL}+0,1 \mathrm{HJ} \mathrm{J}^{2}+0,15 \mathrm{FK} \mathrm{l}$

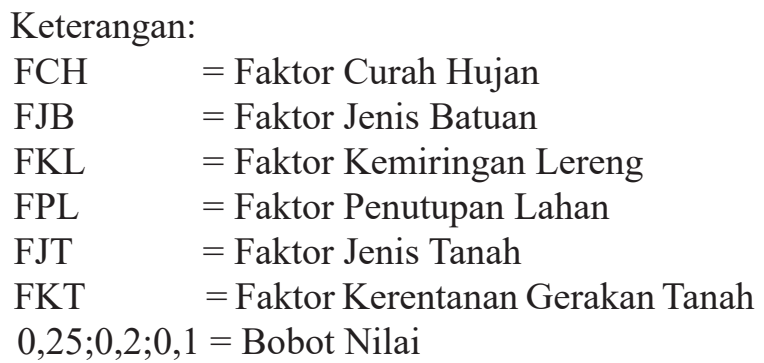

\subsection{Validasi Model Spasial Dengan Kappa Accuracy}

Proses klasifikasi belum sempurna apabila belum menghitung tingkat keakuratannya (Lillesand, 2015). Pada suatu penelitian klasifikasi dikenal dengan istilah The Kappa Index of Agreement (KIA) atau Kappa Accuracy. Menurut Landis dan Koch (1977), range yang mungkin pada Kappa dibagi ke dalam tiga grup yaitu: $>=0.8(80 \%)$ menyatakan strong agreement, $0.4-0.8(40 \%-80 \%)$ menyatakan moderate agreement,$<0.4(40 \%)$ menyatakan poor agreement. Penilaian validasi persentase tiga grup ini dibagi menjadi 2 yaitu penilaian seluruh tingkatan/ overall dengan persamaan (2) dan penilaian Kappa dengan persamaan (3).

$$
\begin{aligned}
& \text { Overall }=\quad \sum_{i=1}^{n} X_{\mu} \times 1000 \% \\
& \text { N } \sum \mathrm{X}, \sum \mathrm{X} \mathrm{X} \\
& \text { N-5X.X }
\end{aligned}
$$




\section{Metode Penelitian}

\subsection{Lokasi Penelitian}

Lokasi penelitian adalah Kabupaten Aceh Tenggara sebagaimana yang ditunjukkan dalam Gambar 1 . Kabupaten Aceh Tenggara mempunyai luas: 4.245,74 $\mathrm{Km} 2$, terdiri dari 16 kecamatan dan secara geografis terletak pada $3^{0} 55^{\prime} 23-4^{0} 16^{\prime} 37$ Lintang Utara dan 96 $43^{\prime} 23^{\circ}-98^{\circ} 10^{\prime} 32$ Bujur Timur dengan ketinggian 25-1000 m diatas permukaan laut serta dikelilingi Taman Nasional Gunung Leuser dan Bukit Barisan (BPS, 2016).

\subsection{Peralatan Penelitian}

Peralatan penelitian ini adalah laptop berisi Windows 10, Microsoft Excel Microsoft Word, ArcGIS 10.6 dan Expert Choice 11 untuk AHP. Telepon pintar (smartphone) Android 7 berisi aplikasi GPS Essential for Android versi 4.4.24 dan Avenza Maps untuk survei lapangan.

\subsection{Jenis Penelitian, Kriteria dan Sumber Data}

Penelitian ini merupakan penelitian deskriptif kuantitatif. Metode penelitian deskriptif kuantitatif adalah sebuah penelitian yang bertujuan untuk memberikan atau menjabarkan suatu keadaan atau fenomena yang terjadi saat ini dengan menggunakan prosedur ilmiah untuk menjawab masalah secara aktual dan dalam bentuk studi kuantitatif yaitu klasifikasi, penilaian, menetapkan standar, dan hubungan kedudukan satu unsur dengan unsur yang lain (Sugiyono, 2012). Sumber data penelitian dikumpulkan berupa data primer dan data sekunder. Data primer diambil langsung oleh peneliti ke lapangan melalui wawancara untuk pembobotan dan skoring dengan metode AHP. Data sekunder dikumpulkan dari dinas-dinas dan badan-badan pemerintah. Data sekunder dalam penelitian ini adalah peta dasar (Bappeda), peta tutupan lahan (Bappeda), peta kemiringan lereng (DEM SRTM, 30 meter), peta gerakan tanah (ESDM) dan peta curah hujan (BMKG).

Kriteria atau parameter dalam penelitian ini adalah peta tutupan lahan, peta kemiringan lereng, peta gerakan tanah dan peta curah hujan. Peta tutupan lahan mempunyai sub-kriteria yaitu pemukiman, hutan lindung, semak belukar, ruang terbuka dan sungai. Peta kemiringan lereng mempunyai sub-kriteria kelas standar dalam persen yaitu 0-8 \%: Datar, 8-15\%: Landai, 15-25\%: Agak Curam, 25-45\%: Curam, $>45 \%$ : Sangat Curam (Syafri, 2015). Peta curah hujan mempunyai sub-kategori yaitu $>3600 \mathrm{~mm} / \mathrm{thn}, 3450$ $3600 \mathrm{~mm} / \mathrm{thn}, 3100-3450 \mathrm{~mm} / \mathrm{thn}$ dan 1600-3100 mm/thn (BMKG, Bappeda kabupaten Aceh Tenggara) dan peta gerakan tanah kabupaten Aceh Tenggara mempunyai sub-kategori yaitu gerakan menengah tinggi dan gerakan menengah (Kementerian ESDM). Kriteria-kriteria ini kemudian menjadi nilai bobot dan Sub-kriteria kemudian menjadi nilai skor. Peta Kriteria dan sub-kriteria ini dirujuk pada penelitian terdahulu (Noorwantoro, Asmaranto, \& Harisuseno, 2014; Prastika \& Sukojo, 2017; Yunianto, 2011).

Badan Penanggulangan Bencana Daerah (BPBD) kabupaten Aceh Tenggara memberikan

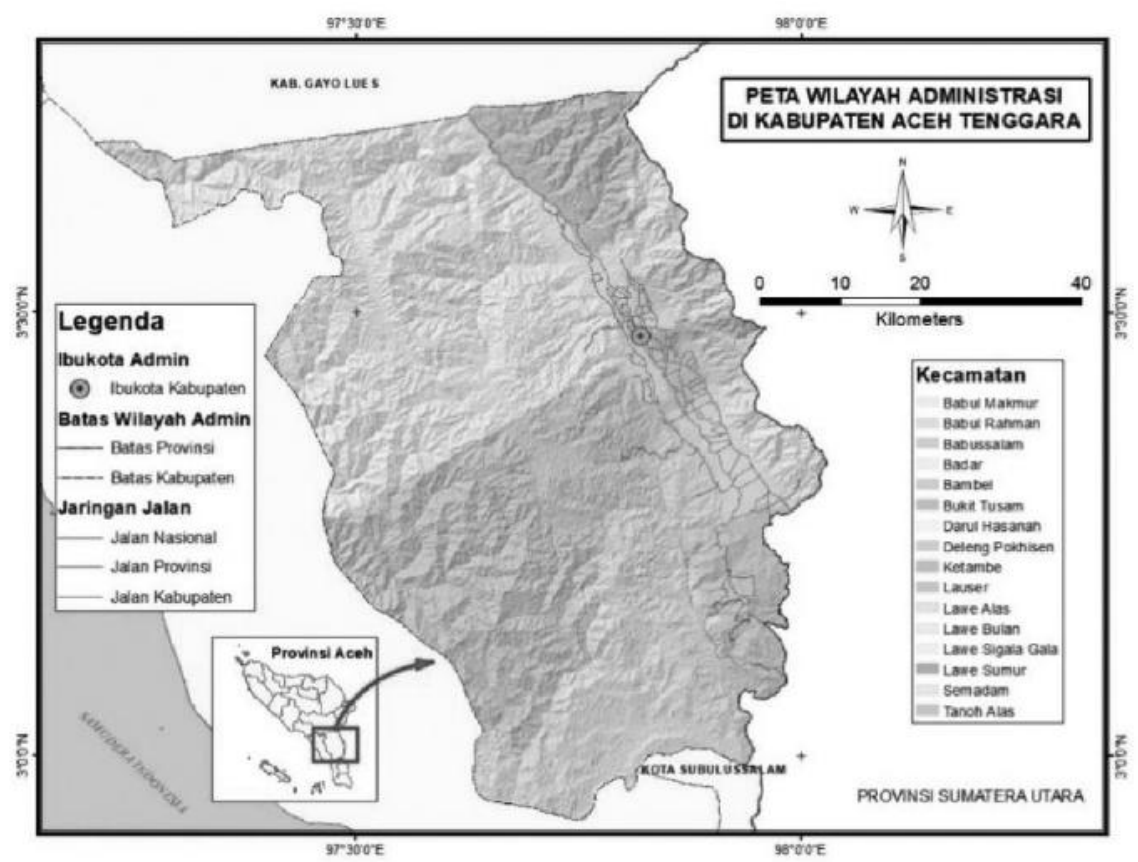

Gambar 1. Peta Kabupaten Aceh Tenggara

Sumber: Bappeda (2018) 


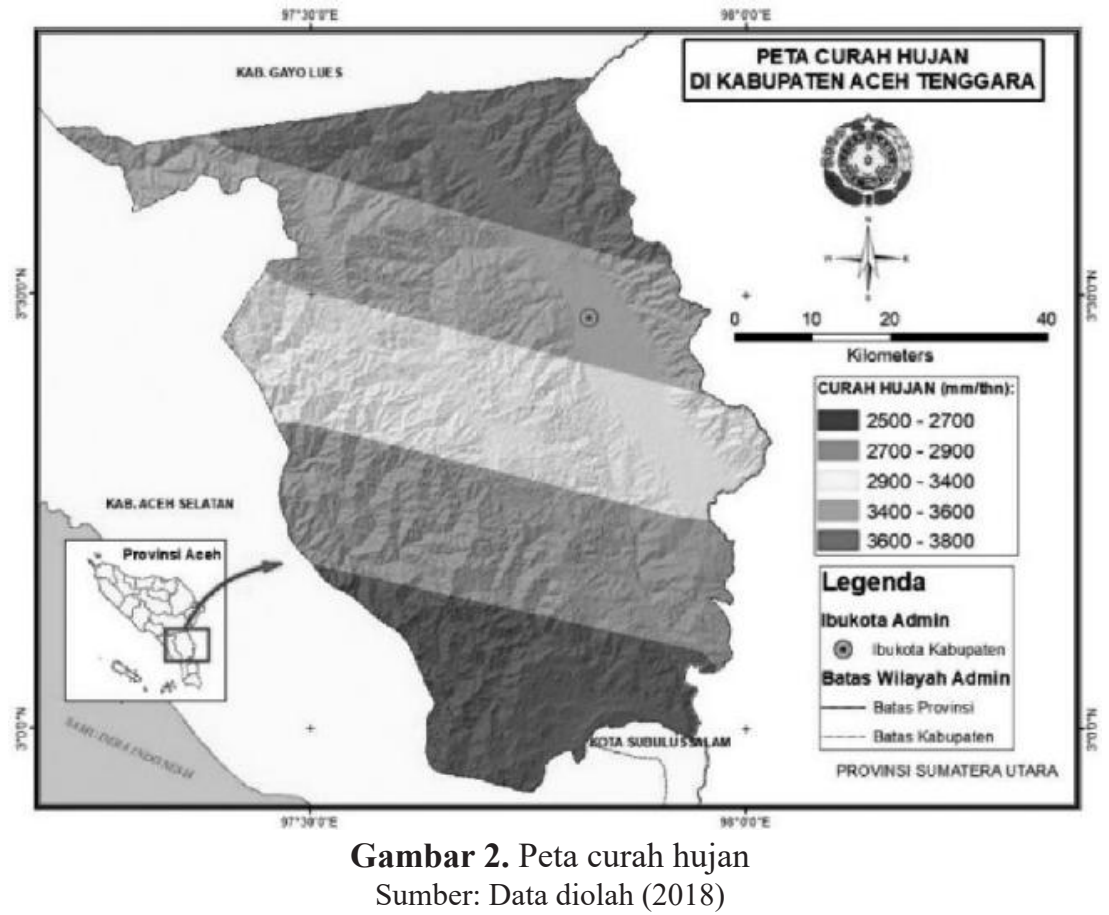

data kejadian longsor tahun 2012 dan 2017. Data ini akan diperiksa ulang ke lapangan sebagai data validasi peta analisis kerawanan longsor dengan bantuan smartphone dengan aplikasi GPS Essential. GPS Essential merekam koordinat tempat kejadian longsor dan beberapa tempat lain sebagai tambahan untuk validasi peta analisa kerawanan longsor.
Populasi penelitian ini adalah beberapa unsur di Kabupaten Aceh Tenggara yang meliputi pemerintah daerah (Bappeda, Dinas PUPR, BPBD), unsur akademisi (dosen), unsur Lembaga Swadaya Masyarkat (LSM) dan unsur masyarakat. Unsur-unsur ini diwakili oleh 1-2 orang sampel untuk diwawancarai dan dianggap ahli sebagai input utamanya.

\subsection{Populasi dan Sample}

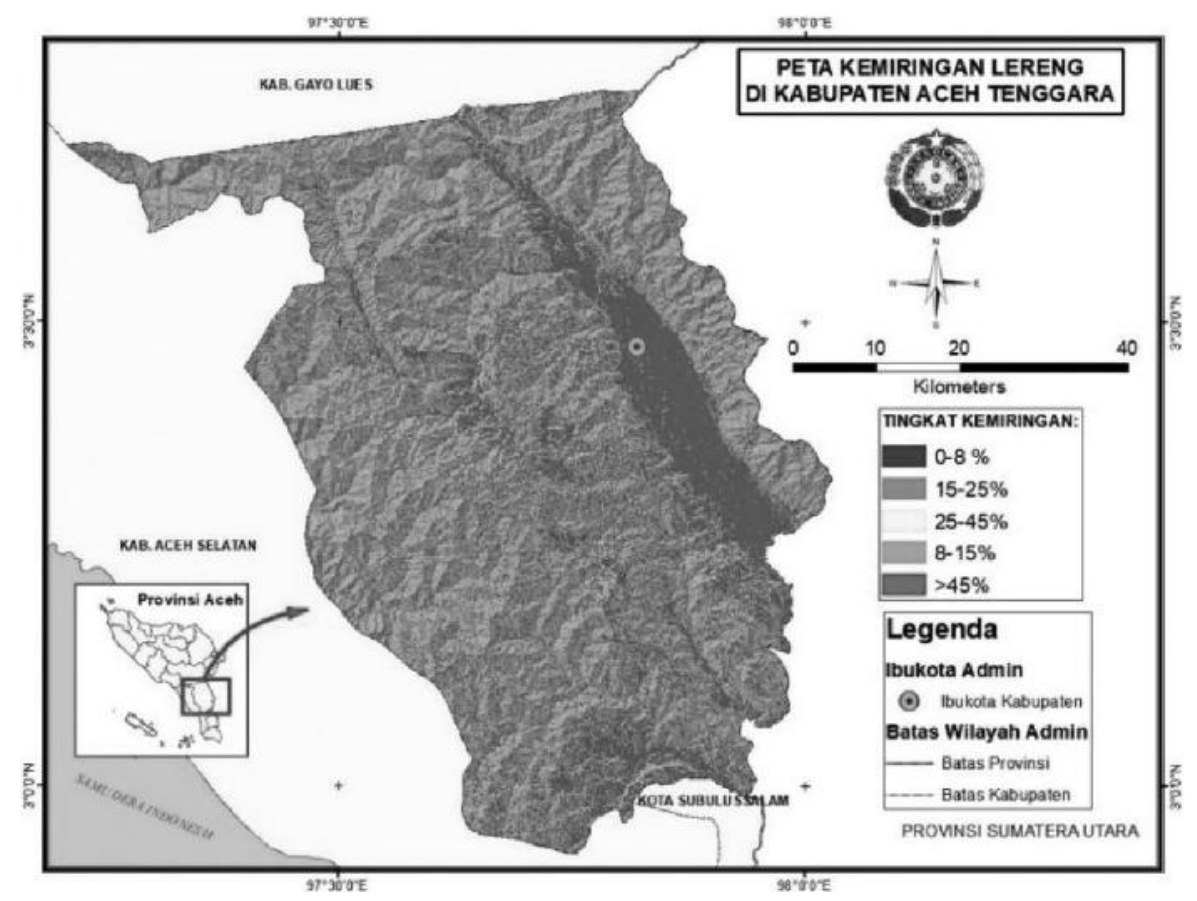

Gambar 3. Peta kemiringan lereng

Sumber: Data diolah (2018) 


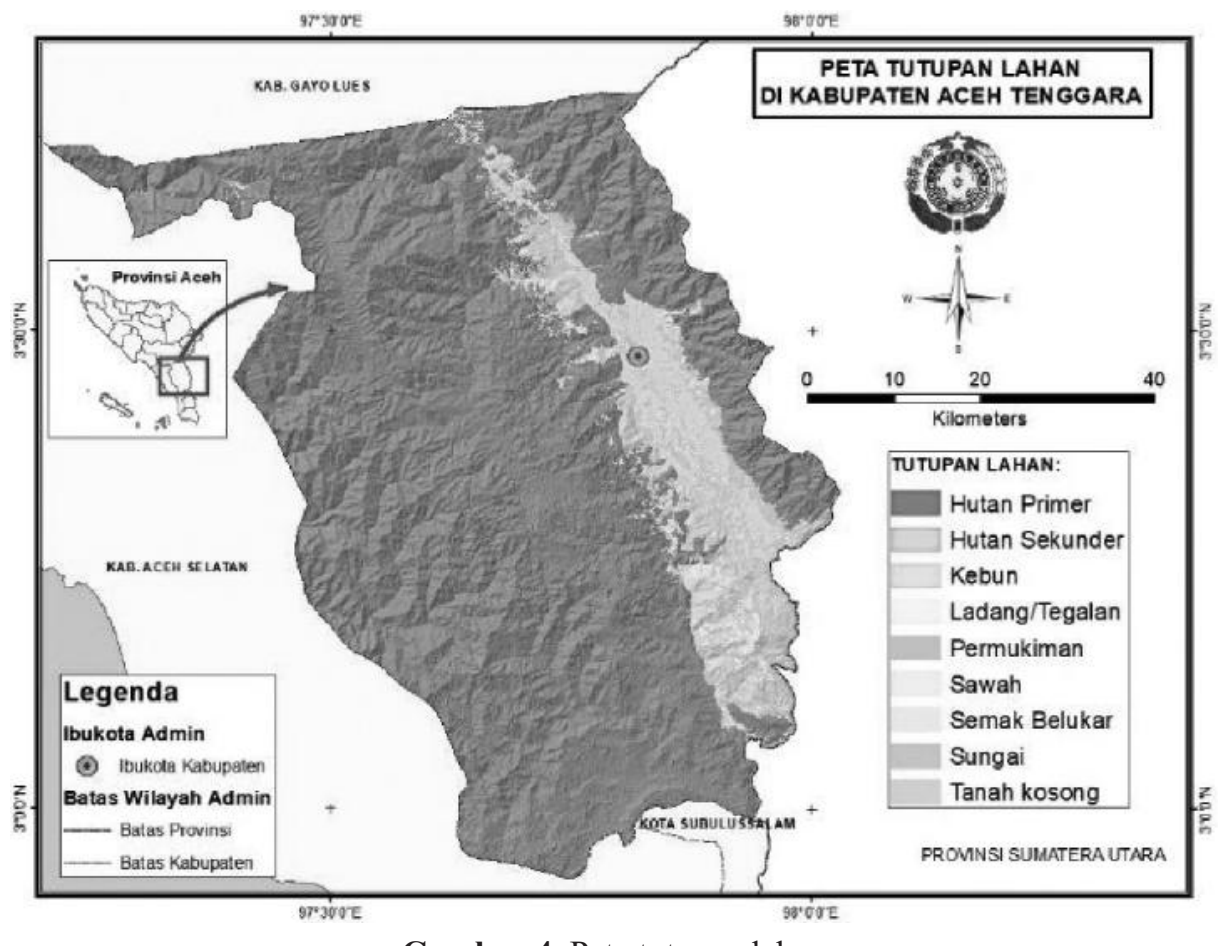

Gambar 4. Peta tutupan lahan

Sumber: Bappeda (2018)

\section{Metode Analisis Data}

\subsection{Analytical Hierarchy Process (AHP)}

Dalam penelitian ini, AHP digunakan untuk menentukan skor dan bobot parameter penyebab tanah longsor. Peneliti memberikan kuesioner yang berisi kriteria dan sub-kriteria penyebab longsor kepada responden dan memasukkan jawaban responden ke dalam aplikasi Expert Choice 11. Expert Choice 11 akan menghitung kriteria mana yang merupakan faktor utama penyebab longsor berdasarkan nilai

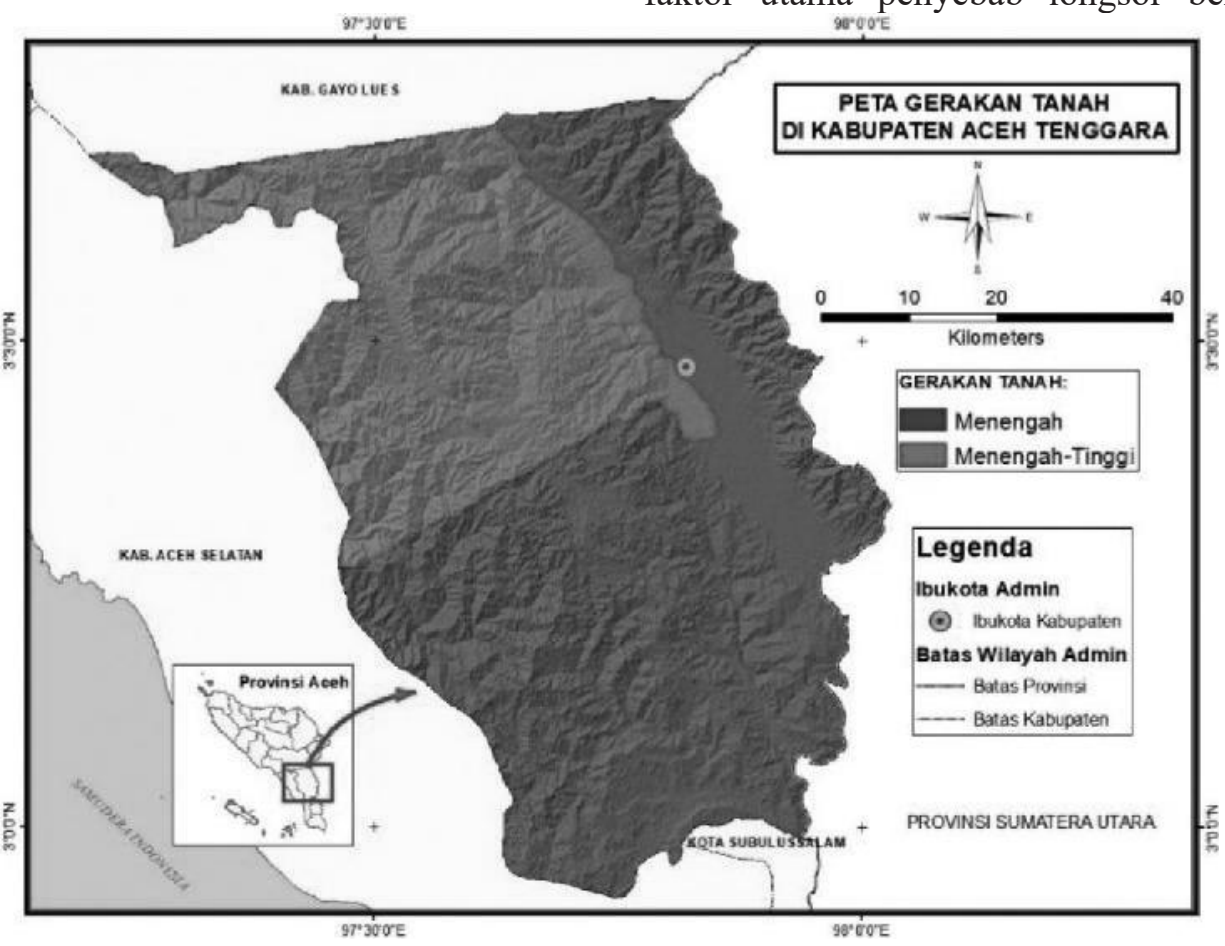

Gambar 5. Peta gerakan tanah Sumber: Data diolah (2018) 


\section{Bobot Kriteria Tanah Longsor}

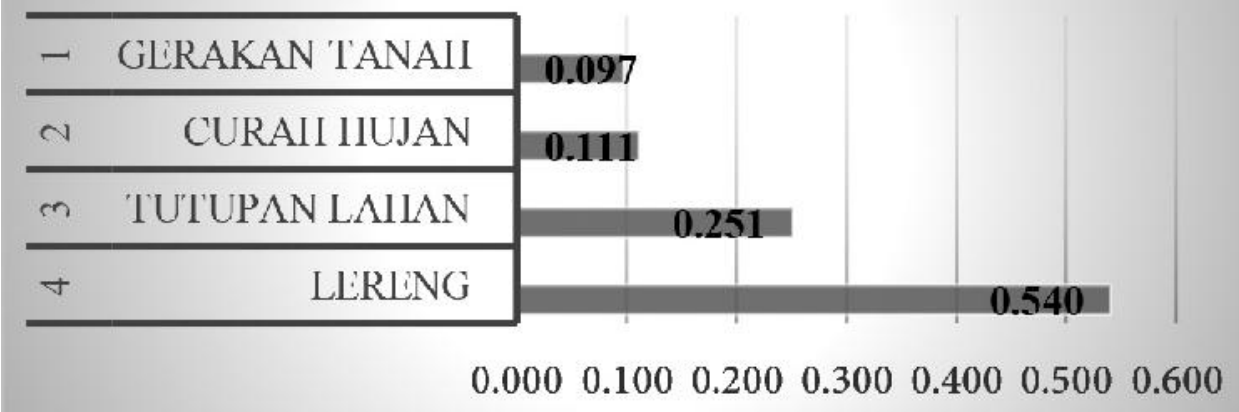

Gambar 6. Grafik nilai bobot longsor

Sumber: Data diolah AHP (2018)

bobot yang paling tinggi (Paharuddin, Hamzah, dan Shakiah, 2016).

\subsection{Pemodelan Spasial dengan Sistem Informasi Geografis (SIG)}

Sistem Informasi Geografis yaitu dengan perangkat lunak ArcGIS melakukan overlay atau tumpang susun kriteria-kriteria longsor. Kriteria-kriteria ini telah dimasukkan nilai bobot dan skor dari AHP sehingga pemodelan pada persamaan (1) yang telah dimodifikasi, dapat dijalankan (Abella \& Van Westen, 2007). Operasi ini menghasilkan peta analisis sebaran tingkat kerawanan longsor dengan 3 (tiga) tingkatan yaitu tinggi, sedang dan rendah.

\subsection{Validasi Model Spasial Dengan Kappa Accuracy}

Proses klasifikasi peta analisis kerawanan longsor belum sempurna apabila belum menghitung tingkat validasi keakuratannya (Lillesand, 2015). Metode validasi yang dipakai adalah metode Kappa Accuracy. Kappa Accuracy membandingkan tingkat persentase kecocokan antara peta analisis kerawanan longsor dengan data lapangan/groundtruth. Semakin tinggi nilai Kappa maka peta analisa kerawanan longsor yang dihasilkan semakin baik dan akurat. Titik referensi sampel groundtruth sering dinamakan producer accuracy sedangkan kelas kerawanan yang dihasilkan oleh peta analisis kerawanan longsor dinamakan user accuracy (Indri Febriani, Lilik Budi Prasetyo, 2017).

Producer accuracy dan User accuracy di overlay di perangkat lunak ArcGIS yang mengelola 2 objek ini menggunakan teknik frequency dan pivot untuk menghasilkan tabel error matrix. Tabel error matrix adalah sebuah tabel yang terdiri dari kolom dan baris yang mewakili sampel untuk keperluan validasi. Kolom biasanya mewakili data referensi/groundtruth/producer sedangkan baris biasanya mewakili klasifikasi yang diperoleh dari model/peta/user (Congalton, 1991)

\section{Hasil dan Pembahasan}

5.1. Peta-Peta Kriteria Penyusun Model Spasial Analisis Kerawanan Longsor

Peta-peta kriteria longsor adalah peta curah hujan, peta kemiringan lereng, peta tutupan lahan dan peta



Gambar 7. Grafik nilai skor kemiringan lereng Sumber: Data diolah AHP (2018) 


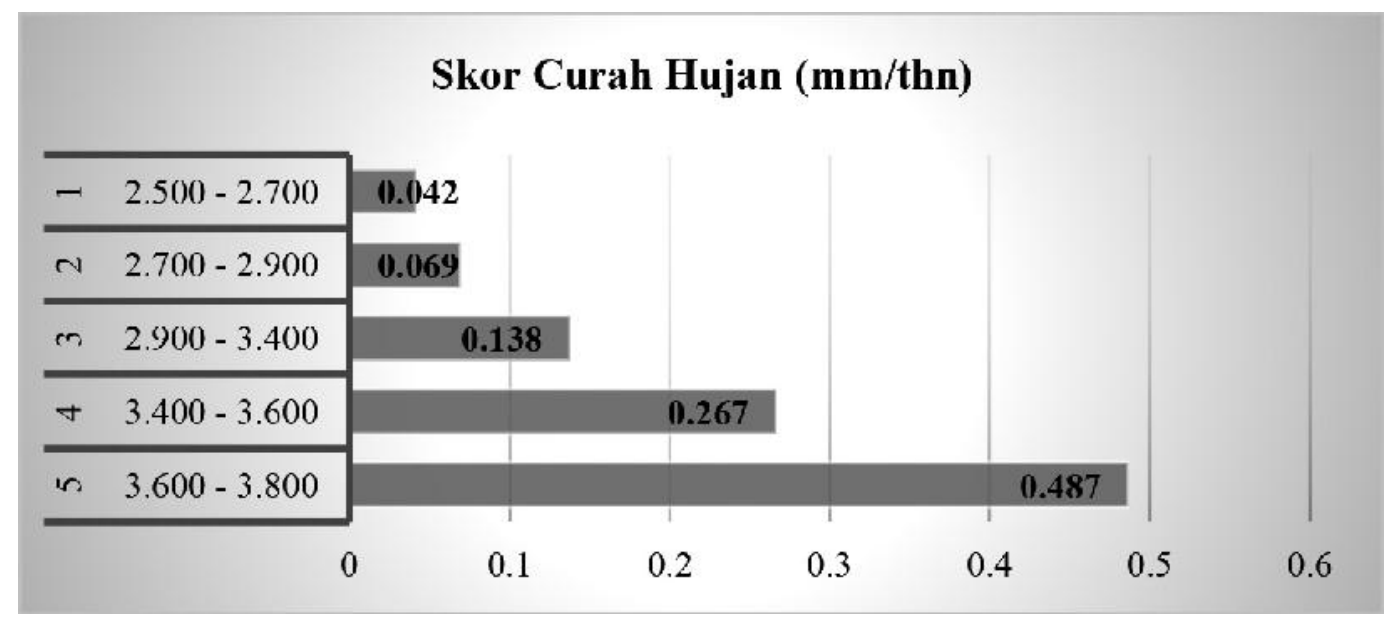

Gambar 8. Grafik nilai skor curah hujan Sumber: Data diolah AHP (2018)

gerakan tanah. Berikut peta-peta kriteria penyusun model spasial analisis kerawanan longsor. Peta curah hujan adalah peta yang dihasilkan dengan metode geostatistikal interpolasi kriging di ArcGIS (Rinjani, 2009). Metode ini menggunakan data curah hujan harian dari stasiun BMKG yang tersebar di provinsi Aceh dan provinsi Sumatera Utara yang berjumlah 15 stasiun. Data yang dipakai adalah data dari tanggal 1 Januari 2017 - 31 Desember 2017 atau data satu tahun. Berdasarkan hasil interpolasi, curah hujan tahunan di Aceh Tenggara berkisar antara $2.500-3.800 \mathrm{~mm} /$ tahun. Gambar 2 menunjukkan peta curah hujan hasil interpolasi.

Peta kemiringan lereng diperoleh dari data DEM SRTM 30 meter dan diproses dengan operasi slope di ArcGIS 10.6. Peta ini memperlihatkan bahwa sebagian besar kabupaten Aceh Tenggara berada di kemiringan sedang sampai curam, hanya sedikit yang mempunyai kawasan landai. Gambar 3 menampilkan peta kemiringan lereng.

Peta tutupan lahan diperoleh dari Bappeda Kabupaten Aceh Tenggara. Gambar 4 menampilkan peta tutupan lahan.

Peta gerakan tanah diperoleh dari Kementerian Energi dan Sumber daya Mineral (ESDM) yang menerbitkan daftar gerakan tanah seluruh kecamatan di Indonesia. Peneliti mengambil data gerakan tanah untuk kabupaten Aceh Tenggara periode Februari 2018. Data ini masih dalam format tabular sehingga perlu di gabung (join) dengan data spasial peta dasar kecamatan di Kabupaten Aceh Tenggara (shp) sehingga menjadi peta gerakan tanah kabupaten Aceh Tenggara. Gambar 5 menampilkan peta gerakan tanah di Kabupaten Aceh Tenggara.

\subsection{Responden dan Hasil Analytical Hierarchy} Process (AHP)

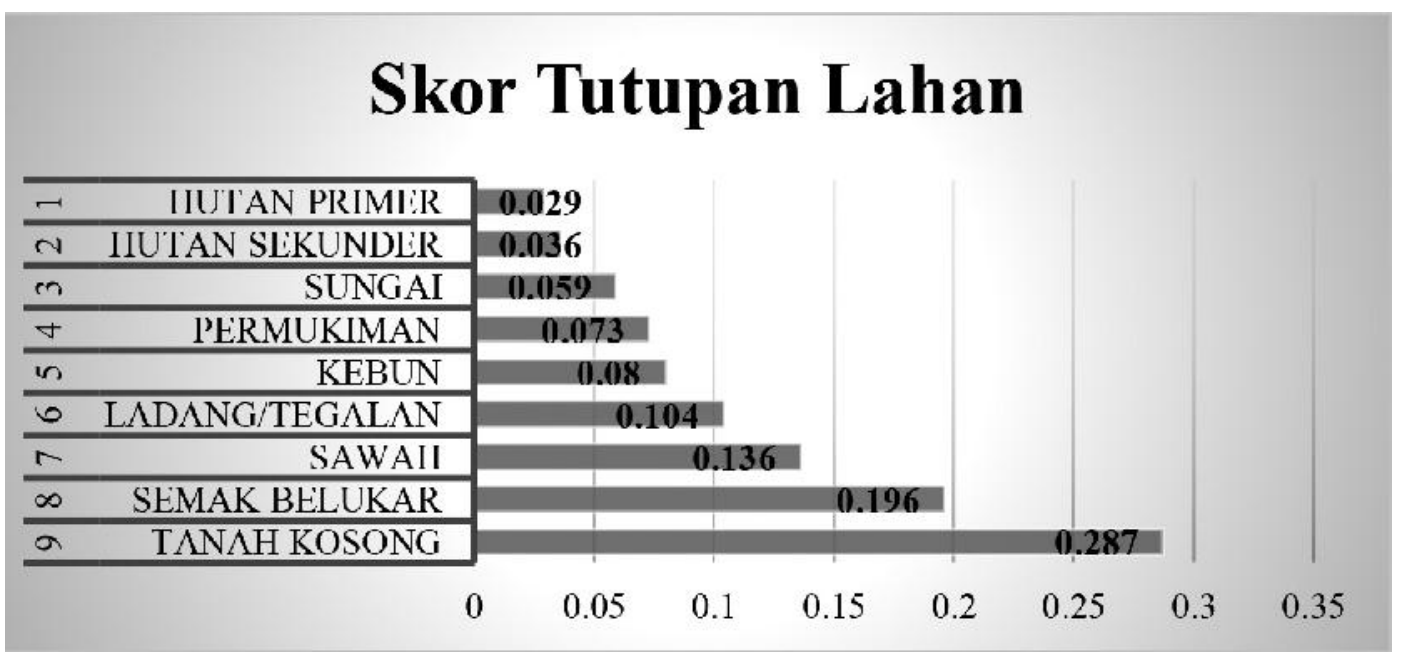

Gambar 9. Grafik nilai skor tutupan lahan Sumber: Data diolah AHP (2018) 


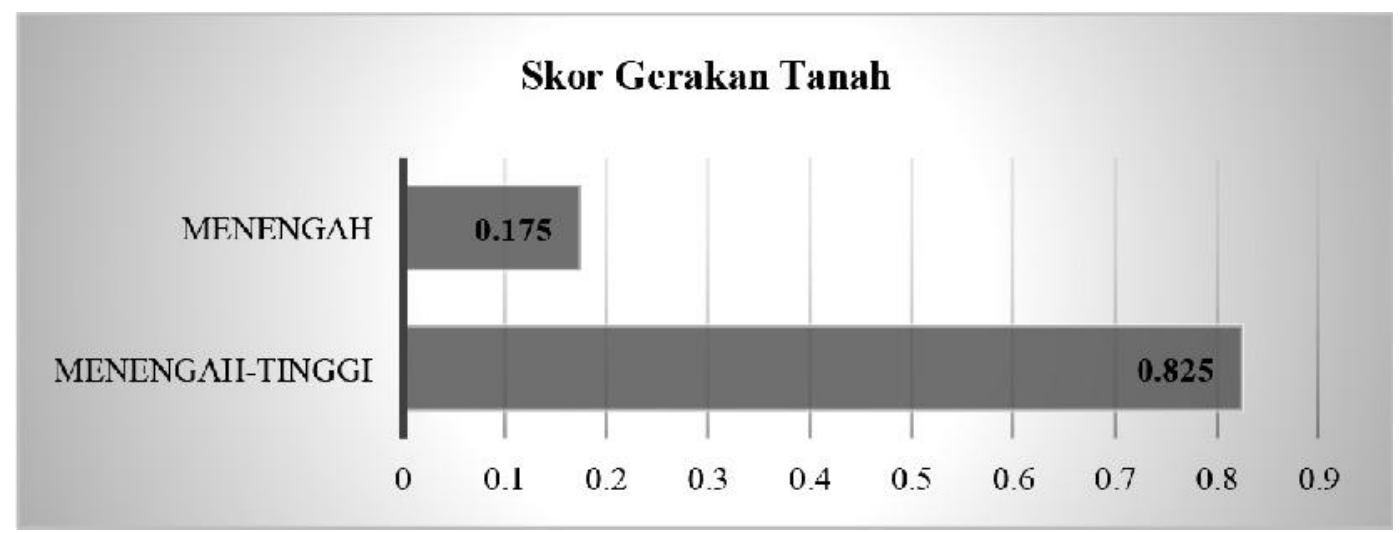

Gambar 10. Grafik nilai skor gerakan tanah Sumber: Data diolah AHP (2018)

Responden yang diwawancarai berjumlah 7 orang yang mewakili unsur pemerintahan, akademisi, LSM dan masyarakat umum. Jawaban responden menunjukkan bahwa kriteria atau faktor kemiringan lereng adalah faktor utama longsor dengan nilai konsisten 0,02. Gambar 6 menunjukkan diagram batang hasil nilai bobot pengolahan Expert Choice.

Hasil ini memberikan gambaran bahwa kemiringan lereng di Kabupaten Aceh Tenggara merupakan faktor utama penyebab longsor. Ini bisa dimaklumi karena observasi lapangan, kabupaten ini dikelilingi oleh perbukitan dengan kemiringan sedang sampai curam.

Untuk nilai skor untuk sub-kategori kemiringan lereng, dimulai dengan skor sub-kategori kemiringan lereng tertinggi sampai terendah yaitu kemiringan 25$45 \%(0,414)$, kemiringan $>45 \%(0,292)$, kemiringan $15-25 \% \quad(0,162), \quad$ kemiringan $8-15 \% \quad(0,081)$, kemiringan $0-8 \%(0,051)$. Inkonsistensi berada pada



Gambar 11. Peta analisis kerawanan longsor Sumber: Data diolah (2018) 
0,06 sehingga skor ini konsisten dan bisa diterima. Gambar 7 menampilkan grafik skor kemiringan lereng.

Nilai skor untuk sub-kategori curah hujan, dimulai dengan skor sub-kategori curah hujan tertinggi sampai terendah yaitu $3.600-3800 \mathrm{~mm} / \mathrm{thn}(0,487), 3.400$ $3.600 \mathrm{~mm} / \mathrm{thn}(0,267), 2.900-3.400 \mathrm{~mm} / \mathrm{thn}(0,138)$, $2.700-2.900 \mathrm{~mm} / \mathrm{thn}(0,069)$ dan $2.500-2.700 \mathrm{~mm} /$ thn $(0,042)$. Inkonsistensi berada pada 0,05 sehingga skor ini konsisten dan bisa diterima. Gambar 8 menunjukkan grafik batang hasil skoring sub-kriteria curah hujan

Nilai skor untuk sub-kategori tutupan lahan, dimulai dengan skor sub-kategori tutupan lahan tertinggi sampai terendah yaitu tanah kosong $(0,287)$, semak belukar $(0,196)$, sawah $(0,136)$, ladang/tegalan $(0,104)$, kebun $(0,08)$, permukiman $(0,073)$, sungai $(0,059)$, hutan sekunder $(0,036)$, hutan primer $(0,029)$. Inkonsistensi berada pada 0,07 sehingga skor ini konsisten dan bisa diterima. Gambar 9 menunjukkan grafik batang hasil skoring sub-kriteria tutupan lahan.

Nilai skor untuk sub-kategori gerakan tanah, dimulai dengan skor sub-kategori gerakan tanah tertinggi sampai terendah yaitu gerakan menengah tinggi $(0,825)$, dan gerakan menengah $(0,175)$. Inkonsistensi berada pada 0,00 sehingga skor ini konsisten dan bisa diterima. Gambar 10 menunjukkan grafik batang hasil skoring sub-kriteria gerakan tanah.

\subsection{Pemodelan Peta Analisis Kerawanan Longsor}

Peta-peta kriteria ini dilakukan operasi overlay dengan perangkat lunak ArcGIS dan menghasilkan peta analisis hasil gabungan 4 (empat) peta kriteria. Peta kriteria ini telah dimasukkan nilai skor dan bobot hasil AHP. Rujukan Pemodelan pada persamaan (1) dimodifikasi menjadi persamaan (4) dibawah kemudian diaplikasikan pada peta analisis ini dan menghasilkan peta analisis kerawanan longsor di Kabupaten Aceh Tenggara dalam 3 (tiga) tingkat yaitu tinggi, sedang dan rendah. Gambar 11 menampilkan peta analisis kerawanan longsor kabupaten Aceh Tenggara. Tabel 1 menampilkan luasan hektar dan persen sebaran kerawanan longsor.

Skor Tulal $-0,11 \mathrm{SCH}+0,097 \mathrm{SGT}+0.25 \mathrm{STL}+0,54 \mathrm{SKL}$

(4)

Keterangan:

$\begin{array}{ll}\text { SCH } & =\text { Skor Curah Hujan } \\ \text { SGT } & =\text { Skor Gerakan Tanah } \\ \text { STL } & =\text { Skor Tutupan Lahan } \\ \text { SKL } & =\text { Skor Tutupan Lahan } \\ 0,11 ; 0,097 ; 0,25 ; 0,54 & =\text { Bobot Nilai Kriteria }\end{array}$

Sebaran kerawanan longsor sedang dan rendah tersebar merata di 14 dari 16 kecamatan di Aceh Tenggara. Kecamatan-kecamatan ini mempunyai kemiringan lereng sedang dan rendah/landai dan berada ke arah Tenggara menuju Sumatera Utara. Sebaran kerawanan longsor tinggi berada di kecamatan Darul Hasanah dan Kecamatan Ketambe meskipun secara persentase kerawanan tingkat tinggi hanya $13 \%$ tapi kecamatan ini berada di arah Barat Laut dan memiliki kemiringan lereng yang tinggi yang bersambung dengan kawasan dataran tinggi Gayo. Kedua kecamatan ini juga berada dalam kawasan Taman Nasional Gunung Leuser. Kerawanan longsor tinggi ini juga berada pada jalur transportasi utama yaitu jalan nasional Kutacane - Gayo Lues yang bisa menyebabkan permasalahan serius seperti putusnya kegiatan perekonomian atau transportasi.

\subsection{Validasi Model Spasial Dengan Kappa Accuracy}

Groundtruth dilakukan pada lokasi kejadian longsor pada tahun 2012 dan tahun 2017 yang diperoleh dari BPBD kabupaten Aceh Tenggara sebanyak 27 titik. Peneliti menambah beberapa titik lain yang dianggap mewakili kerawanan longsor. Total data groundtruth yang telah diperoleh dari lapangan adalah 48 titik. Seluruh titik ini diberikan kode kerawanan longsor 1 (tinggi), 2 (sedang), 3 (rendah). Kode ini juga diberikan kepada peta analisis kerawanan longsor yang telah dihasilkan pada gambar 11 diatas. Sehingga data groundtruth dan peta analisis memiliki kode yang sama. Data groundtruth dan model kemudian dioverlay untuk dilakukan perhitungan kappa accuracy. Tabel 2 menampilkan tabel error matrix dan nilai user, producer, overall dan kappa accuracy.

Rerata producer dan user menunjukkan hasil diatas 80\%. Overall accuracy dan nilai Kappa masing-masing menunjukkan hasil $79 \%$ dan $69 \%$ maka model spasial yang dibuat dapat diterima dan valid. Rerata producer dengan persentase yang tinggi menginformasikan bahwa pengambilan data lapangan dilapangan telah dilakukan dengan baik. Demikian juga dengan rerata user yang menunjukkan persentase tinggi, ini menunjukkan pembuatan model spasial telah dilakukan dengan baik. Namun secara keseluruhan,

Tabel 1. Luas dan persentase sebaran kerawanan longsor

\begin{tabular}{lll}
\hline Tingkat Longsor & Luas (Ha) & Persen \\
\hline Rendah & $209.523,56$ & $49 \%$ \\
Sedang & $158.170,14$ & $37 \%$ \\
Tinggi & $56.640,76$ & $13 \%$ \\
Total & $424.334,46$ & $100 \%$ \\
\hline
\end{tabular}

Sumber: Hasil analisa (2018) 
Tabel 2. Tabel error matrix

\begin{tabular}{ccccccc}
\hline & \multicolumn{7}{c}{ Groundtruth/Producer } & & \\
& & $\mathbf{1}$ & $\mathbf{2}$ & $\mathbf{3}$ & Total & Producer Accuracy \\
\hline \multirow{3}{*}{ Model/User } & $\mathbf{1}$ & 9 & 0 & 0 & 9 & $100 \%$ \\
& $\mathbf{2}$ & 1 & 16 & 2 & 19 & $84 \%$ \\
& $\mathbf{3}$ & 7 & 0 & 13 & 20 & $65 \%$ \\
User Accuracy & Total & 17 & 16 & 15 & 48 & \\
\hline
\end{tabular}

Sumber: Hasil analisa (2018)

$\begin{array}{lll}\text { Rerata Producer: } & 83 \% & \text { Keterangan: } \\ \text { Rerata User: } & 80 \% & 1=\text { Rawan Longsor Tinggi } \\ \text { Overall: } & 79 \% & 2 \text { = Rawan Longsor Sedang } \\ \text { Kappa: } & 69 \% & 3=\text { Rawan Longsor Rendah }\end{array}$

perpaduan antara producer dan user manunjukkan penurunan di angka 79\% dan nilai kesepakatan Kappa antara keduanya juga menurun drastis di angka 69\%. Meskipun masih berada di kelas moderate, namun nilai Kappa mungkin dapat ditingkatkan dengan memperbanyak data groundtruth.

\section{Kesimpulan}

Penelitian ini telah menghasilkan suatu produk peta analisa sebaran kerawanan longsor di kabupaten Aceh Tenggara. Peta ini adalah integrasi antara metode pembobotan dan skoring AHP dengan aplikasi Expert Choice 11 dan pemodelan spasial menggunakan Sistem Informasi Geografis dengan aplikasi ArcGIS 10.6. Kesimpulan sesuai dengan tujuan penelitian ini adalah:

1. Kriteria/Faktor utama terjadinya bencana longsor di kabupaten Aceh Tenggara adalah kemiringan lereng. Ini bisa diterima karena secara observasi lapangan, kabupaten ini berada diantara perbukitan dan pegunungan.

2. Penelitian telah menghasilkan sebaran spasial kerawanan longsor dengan sebaran tingkat kerentanan rendah 209.523,56 $\mathrm{Ha}$ (49\%), kerentanan sedang $158.170,14 \mathrm{Ha}(37 \%)$ dan kerentanan tinggi 56.640,76 (13\%). Walaupun persentase tingkat kerentanan tinggi kecil namun kerentanan tinggi ini mencakup area yang cukup luas dan ada bagian jalan nasional yang menghubungkan antar kabupaten, jalan provinsi dan jalan kabupaten yang masuk dalam kawasan kerentanan tinggi ini.

\section{Daftar Pustaka}

Abella, E A Castellanos, and C J Van Westen. 2007. "Generation of a Landslide Risk Index Map for Cuba Using Spatial Multi-Criteria Evaluation."
Landslides 4(4): 311-25. https://doi.org/10.1007/ s10346-007-0087-y.

Aronoff, Stanley. 1989. Geographic Information System; A Management Perspective. Ottawa: WDL Publications.

BBSDLP, Balai Besar Litbang Sumberdaya Lahan Pertanian. 2009. Identifikasi Dan Karakterisasi Lahan Rawan Longsor Dan Rawan Erosi Di Dataran Tinggi Untuk Mendukung Keberlanjutan Pengelolaan Sumberdaya Lahan Pertanian. Laporan Tengah Tahun, DIPA 2009. Bogor.

BPBD. 2012. Rekapitulasi Bencana Kebakaran Dan Bencana Alam Penanggulangan Bencana Daerah Kabupaten Aceh Tenggara.

BPS, Kabupaten AcehTenggara. 2016. Kabupaten Aceh Tenggara Dalam Angka 2016. Aceh Tenggara: BPS Kabupaten Aceh Tenggara.

Congalton, Russell G. 1991. "A Review of Assessing the Accuracy of Classifications of Remotely Sensed Data." Remote Sensing of Environment. - 2017. Rekapitulasi Bencana Kebakaran Dan Bencana Alam Penanggulangan Bencana Daerah Kabupaten Aceh Tenggara.

Hummel, Dr. J M et al. 1998. "The Analytic Hierarchy Process: An Effective Tool for a Strategic Decision of a Multidisciplinary Research Center." Knowledge, technology and policy.

Indri Febriani, Lilik Budi Prasetyo, Arya Hadi Dharmawan. 2017. "Analisis Deforestasi Menggunakan Regresi Logistik Model Di Tahura Sekitar Tanjung Provinsi Jambi." Jurnal Pengelolaan Sumberdaya Alam dan Lingkungan 7: 195-203.

Landis, J Richard, and Gary G Koch. 1977. "The Measurement of Observer Agreement for Categorical Data." Biometrics. 
Lillesand, Thomas M. 2015. Remote Sensing and Image Interpretation. 7th ed. Hoboken, $\mathrm{NJ}$ : Wiley.

Noorwantoro, Muhammad, Runi Asmaranto, and Donny Harisuseno. 2014. "Analisa Kawasan Rawan Bencana Tanah Longsor Di Das Upper Brantas Menggunakan Sistem Informasi Geografi."

Paharuddin, Muh. Alimuddin Hamzah, and Rezky Shakiah. 2016. Analisis Spasial Rawan Longsor Di Kabupaten Toraja Utara. Makassarr.

Prastika, Citra, and Bangun Muljo Sukojo. 2017. "Analisis Bencana Longsor Lahan Di Kabupaten Tuban Melalui Pengolahan Citra Satelit Multilevel Untuk Pembuatan Peta Potensi Longsor.” Jurnal Teknis ITS 6 no 2: 2337-3520.

Rinjani, Suskia. 2009. "Pembangunan Model Untuk
Pembuatan Pola Kecepatan Kendaraan Di RuasRuas Jalan Jakarta Pusat." Institut Teknologi Bandung.

Saaty, T L. 1980. The Analytic Hierarchy Process: Planning, Priority Setting, Resource Allocation. RWS Publications. https://books.google.co.id/ books?id=fhkKMQAACAAJ.

Sugiyono. 2012. Penerbit Alfabeta Statistika Untuk Penelitian.

Syafri, Sriwahyuni Hi. 2015. "Identifikasi Kemiringan Lereng Di Kawasan Permukiman Kota Manado Berbasis SIG." SPASIAL Vol 1.

Yunianto, Ardi Chandra. 2011. "Analisis Kerawanan Tanah Longsor Dengan Aplikasi Sistem Informasi Geografis (SIG) Dan Penginderaan Jauh Di Kabupaten Bogor.” 